\title{
RELAÇÕES E INTERAÇÕES DOS PROFESSORES DE CIÊNCIAS E MATEMÁTICA COM AS TECNOLOGIAS
}

\author{
E. J. Ramos $^{1}$ e L. H. Amaral ${ }^{2}$ \\ ${ }^{1}$ CEFET-MG, ${ }^{1}$ Bolsista CAPES e ${ }^{1,2}$ Universidade Cruzeiro do Sul \\ ijramos@deii.cefetmg.br ${ }^{1}$ - luiz.amaral@cruzeirodosul.edu.br ${ }^{2}$
}

Artigo submetido em junho/2012 e aceito em agosto/2012

\section{RESUMO}

As Tecnologias da Informação e Comunicação (TICs) sinalizam possíveis transformações e uma reforma nos sistemas de educação. Sabe-se que as mídias por si só, tomadas isoladamente, não irão influenciar o desempenho dos estudantes. É com essa crença que, neste trabalho, se investiga como ocorrem as relações e interações dos professores de Ciências e Matemática com as Tecnologias. O trabalho teve uma abordagem qualitativa e os dados foram coletados por meio de um questionário aplicado a 57 professores que trabalham com o Ensino de Ciências e Matemática no Ensino Médio. Como resultados observou-se que; a maioria dos professores possui uma relação e interação amigável com a informática e com a internet, entretanto as relações e interações com os Ambientes Virtuais de Aprendizagem e com os Objetos de Aprendizagem são incipientes; alguns professores utilizam tecnologias em seu trabalho docente; recebeu destaque o uso da internet e do e-mail; a maior parte dos professores reconheceu a potencialidade das Tecnologias da Informação e Comunicação no processo de ensino e aprendizagem; os professores apontam muitas vantagens e desvantagens para o uso das tecnologias aplicadas à educação.

PALAVRAS-CHAVE: O uso das TICs na educação, Ambientes Virtuais de Aprendizagem, Objetos de Aprendizagem.

\section{RELATIONSHIPS AND INTERACTIONS OF MATHEMATICS AND SCIENCE TEACHERS WITH TECHNOLOGY}

\section{ABSTRACT}

Information and Communications Technology (ICTs) indicate possible changes and transformations in the educational system. It is known that the media by itself will not influence the students' performance. It is with this belief that this study aims to investigate how occur the interactions and reactions of the Science and Math teachers with the ICTs. This study had a qualitative approach and the data were collected through a questionnaire applied to 57 teachers of Science and Mathematics in high school. Some of the findings were: most teachers have a friendly interaction and relationship with the computer and the internet although the relationship and interaction with Virtual Learning Environments and Learning Objects are incipient; some of the teachers questioned use technology in their teaching, it was highlighted the use of the Internet and e-mail; most of the teachers recognize the potentiality of ICTs in the teaching and learning process; the teachers point many advantages and disadvantages of the use of technologies applied to education .

KEY-WORDS: Use of ICT in Education, Learning Virtual Environment, Learning Objects. 


\section{RELAÇÕES E INTERAÇÕES DOS PROFESSORES DE CIÊNCIAS E MATEMÁTICA COM AS TECNOLOGIAS}

\section{INTRODUÇÃO}

Segundo Castells (1999), na segunda metade da década de 1990, teve início a fusão da mídia de massa personalizada, globalizada com a comunicação mediada por computadores. Este novo sistema foi caracterizado pela integração de diferentes veículos de comunicação e de seu potencial interativo. Multimídia como o novo sistema logo foi chamado, estende o âmbito da comunicação eletrônica para todo o domínio da vida: de casa ao trabalho, de escolas a hospitais, de entretenimento a viagens (CASTELLS, 1999). Lévy (1999) completa afirmando ser um horizonte de unimídia multimodal, ou seja, a constituição progressiva de uma estrutura de comunicação integrada, digital e interativa, chamado de ciberespaço.

Neste ciberespaço, segundo Heide e Stilborne (2000), a Internet é uma ferramenta que se torna cada vez mais importante para o processo de ensino e aprendizagem, em que as Tecnologias da Informação e Comunicação (TICs) têm um potencial transformador na maneira como os professores podem ensinar e os estudantes podem aprender.

A educação encontra-se em um momento conflituoso e desafiador caracterizado pela constante mudança. Sabe-se que a Internet aproxima-nos da promessa de favorecer a aprendizagem, sinalizando possíveis transformações de uma reforma nos sistemas de educação, propiciadas pelas TICs. Sabe-se também que as mídias por si só, tomadas isoladamente, não irão influenciar o desempenho dos estudantes (LÉVY, 1999; HEIDE e STILBORNE, 2000; WARSCHAUER, 2006 e FELDKERCHER e MATHIAS, 2010).

Marshall Mcluhan, segundo Heide e Stilborne (2000), complementa ao destacar que se nenhuma força direcionada fizer com que as novas mídias sejam utilizadas de novas maneiras, então as tecnologias serão sempre utilizadas para realizar trabalho velho. Ou seja, usa-se o novo para trabalhar de forma antiga. Para que isso seja evitado, faz-se necessário que o ensino seja trabalhado de forma a propiciar ao estudante aprender de forma significativa. Aprender de forma significativa para Ausubel, segundo Moreira e Masini (2001), é um processo pelo qual uma nova informação se relaciona com um aspecto relevante da estrutura de conhecimento do indivíduo.

Ao refletir sobre a afirmativa feita por Marshall Mcluhan, pode-se questionar: até o presente momento, essa tem sido a experiência com as TICs na educação?

Heide e Stilborne (2000) respondem afirmando que não é o tipo de tecnologia disponível em sala de aula, mas sim como ela é utilizada. Como qualquer coisa na vida, o valor de uma tecnologia está diretamente ligado a sua aplicação. Warschauer (2006) afirma que a tecnologia auxilia muitíssimo os estudantes quando não é o único ou o principal foco do processo de ensino e aprendizagem. Para Sandholtz et al. (1997), embora o papel das TICs deva ir muito além de simples máquinas de ensinar, a tecnologia é apenas uma ferramenta entre muitas.

Lévy (1993) afirma que muitas vezes ouve-se dizer que a técnica em si mesma não é nem boa nem má, e que tudo o que conta é o uso que se faz dela e o uso que o "usuário final" faz é que determina se é boa ou má. 
Usar as TICs apenas para realizar atividades de instrução programada é usá-la com um papel secundário. Não se pode pensar em usá-las com o único fim de realizar atividades baseadas no trabalho de repetição, ou seja, baseada na teoria behaviorista. Nessas condições, não oportuniza e nem capitaliza os verdadeiros potenciais das tecnologias. Acredita-se que essa potencialidade poderia ser conseguida se fosse usada com base nas teorias do desenvolvimento cognitivo e construtivista.

Ao se considerar a teorias do desenvolvimento cognitivo e construtivista, pode-se pensar em utilizar as TICs para propiciar aos aprendizes possibilidades de desenvolver suas habilidades cognitivas de ordem superior, bem como; acessar, armazenar, manipular e analisar informações. Dessa forma, os estudantes podem usar melhor seu tempo na reflexão, no entendimento e na compreensão dos conceitos a serem apreendidos.

Essa geração que nasceu e cresce interagindo com a multimídia multidimensional e interativa tem expectativas e visão de mundo diferentes da geração que a precedeu. Para se ter uma educação apropriada a essa geração de estudantes o sistema educacional deve considerar as transformações culturais ocorridas. Para tanto, faz-se necessário que o sistema educacional tenha suas práticas revisadas sob essa nova ótica.

Os estudantes necessitam de um professor que considere as TICS como um meio para novos fins, para um ensino mais dinâmico, sem ter nas tecnologias a questão principal, mas tendo nas novas formas de percepção e na consciência a questão principal. Essas se fazem necessárias devido às mudanças, às novas formas de entendimento do que significa produzir conhecimento. Faz-se necessário, ainda, ter disposição em substituir antigas didáticas por novas mais democráticas que atualmente são encontradas no ambiente da comunidade de aprendizagem. Para Heide e Stilborne (2000), com o uso das TICs, a sala de aula pode se tornar um ambiente de aprendizagem mais cooperativo, na qual o professor trabalha de forma a fornecer a direção, a orientação e a inspiração.

Feldkercher e Mathias (2010) afirmam que as TICs trazem novas exigências ao trabalho docente, tais como; conhecer as tecnologias, identificar possibilidades e limites do uso de cada tecnologia, desenvolver novas tecnologias para o processo de ensino e aprendizagem, entre outras. Portanto,

\footnotetext{
fazem-se necessárias novas metodologias que levam em consideração essa nova possibilidade de ensino, pois não bastam tecnologias para que a aprendizagem ocorra. $E$, para que os professores adotem novas tecnologias, eles precisam conhecê-las, usá-las, identificar suas vantagens e limites o que pode ocorrer por meio de cursos, pela autoformação e por vivências/experiências (FELDKERCHER e MATHIAS, 2010, p. 39).
}

Assim, percebe-se que os caminhos que a educação trilhará irão passar pelo mundo das TICs. Seu uso cresce em todos os segmentos da sociedade, transformando-a. A educação como resultado de uma cultura não conseguirá escapar a essa transformação. A questão atual é saber se o professor está pronto para se relacionar e interagir com as TICs. Por essa perspectiva, em que o profissional da educação necessita de novas habilidades e competências, questiona-se: como ocorrem as relações e interações dos professores com as TICs? Em particular, como ocorrem as relações e interações dos professores de Ciências e Matemática com as TICs? 
O reconhecimento do potencial de uso dos recursos das TICs no processo de ensino e aprendizagem, por possibilitarem novas formas de ensinar e de aprender, levou a este estudo de como ocorrem as relações e interações dos professores com as TICs. Assim, o objetivo central deste trabalho é investigar como ocorrem as relações e interações dos professores de Ciências (Física, Química e Biologia) e Matemática com as TICs.

\section{CARACTERIZAÇÃO DA METODOLOGIA E DO SUJEITO}

Para se estudar as relações e interações dos professores com as TICs, optou-se por realizar a pesquisa com uma abordagem qualitativa, preocupando-se mais com o significado dos dados e com a compreensão do fenômeno do que com as quantidades (MINAYO, 1986).

A coleta de dados foi realizada no período de outubro a novembro de 2011 . Foram entregues questionários a 60 professores que lecionam Ciências e Matemática, no Ensino Médio, vinculados a uma instituição de educação tecnológica situada no estado de Minas Gerais ${ }^{1}$. Dos 60 questionários, 57 foram respondidos e devolvidos ao pesquisador. Dos professores

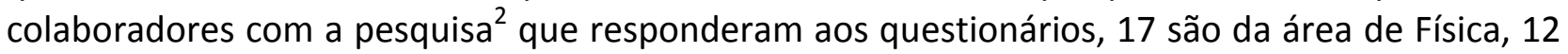
de Química, 9 de Biologia e 19 de Matemática. No texto, os professores de Física foram denominados por PF1, PF2, ... PF17, os de Química por PQ1, PQ2, ... PQ12; os de Biologia por PB1, PB2, ... PB9, e os de Matemática PM1, PM2, ..., PM19, a fim de resguardar suas identidades. Adotou-se como instrumento de coleta de dados um questionário destinado a captar as percepções dos professores. Para facilitar a análise criaram-se as seguintes categorias: Caracterização do sujeito; Relação e interação com: a informática; a internet; os ambientes virtuais de aprendizagem (AVAs); os objetos de aprendizagem (OA) e as Tecnologias da Informação e Comunicação (TICS). Os dados coletados foram trabalhados com apoio da análise de conteúdo, proposta por Bardin (2010), seguindo as fases de pré-análise; exploração do material; o tratamento dos resultados, a inferência e a interpretação.

Seis questões, relativas à caracterização do sujeito, procuraram qualificar quanto ao sexo; faixa etária; formação; regime de trabalho; tempo que leciona e tempo que leciona na instituição.

Referente à distribuição do gênero da amostra, observou-se os seguintes dados: 35 são do sexo masculino e 22 do sexo feminino. Os dados mostram que ainda há um desequilíbrio na relação entre mulheres e homens trabalhando com o Ensino de Ciências e Matemática.

A segunda questão procurou identificar a idade dos professores. Os dados foram tabulados e a distribuição feita por intervalo de idade, em anos, e está apresentada no Quadro 1.

Quadro 1: Distribuição por faixas etárias.

\begin{tabular}{|c|c|c|c|c|}
\hline $20 \mid-30$ & $30 \mid-40$ & $40 \mid-50$ & $50 \mid-60$ & $60 \mid-70$ \\
\hline 5 & 20 & 14 & 10 & 8 \\
\hline
\end{tabular}

\footnotetext{
${ }^{1}$ Instituição de educação tecnológica doravante será denominada apenas por instituição.

${ }^{2}$ Professores colaboradores com a pesquisa, de agora em diante no texto serão denominados apenas por professores.
} 
Fonte: dados da pesquisa

Cabe destacar que 34 dos 57 professores estão na faixa etária dos 30 a 50 anos.

A terceira questão procurou identificar a formação do professor em que se considerou a maior titulação para tabular os dados. Essa tabulação é apresentada no Quadro 2.

Quadro 2: Distribuição por titulação.

\begin{tabular}{|c|c|c|c|}
\hline Graduação & Especialização & Mestrado & Doutorado \\
\hline 6 & 11 & 25 & 15 \\
\hline
\end{tabular}

Fonte: dados da pesquisa

Os dados mostram que o número de professores que possui apenas graduação (6) é relativamente pequeno comparado com o total de professores (57). Outra observação que se pode retirar dos dados é que o número de professores que possui mestrado e/ou doutorado (40) é bem significativo em relação ao número total de professores (57). Isto provavelmente deve-se ao perfil da Instituição analisada, visto não ser este o perfil de titulação nas escolas públicas que atuam no ensino médio no Brasil.

A quarta questão procurou identificar o regime de trabalho dos professores investigado. O Quadro 3 mostra a distribuição dos dados no quesito regime de trabalho.

Quadro 3: Distribuição por regime de trabalho.

\begin{tabular}{|c|c|c|c|}
\hline DE & E40 & S40 & S20 \\
\hline 33 & 3 & 17 & 4 \\
\hline
\end{tabular}

Fonte: dados da pesquisa

Legenda

DE - Efetivo Dedicação Exclusiva

E40 - Efetivo Quarenta horas

S40 - Substituto quarenta horas

S20 - Substituto vinte horas

Dos dados pode-se observar que o número de professores substitutos representa uma parte significativa do quadro de professores. Ou seja, são 21 professores substitutos de um quadro de $60^{3}$ professores atuantes na área de Ensino de Ciências e Matemática na instituição.

A quinta questão procurou identificar o tempo de trabalho dos professores no magistério. O Quadro 4 mostra a distribuição por faixas, em anos, de tempo de magistério dos professores.

${ }^{3}$ Os três professores que não devolveram o questionário são professores efetivos. 
Quadro 4: Distribuição por tempo de trabalho no magistério.

\begin{tabular}{|c|c|c|c|c|c|c|c|}
\hline $0 \mid-5$ & $5 \mid-10$ & $10 \mid-15$ & $15 \mid-20$ & $20 \mid-25$ & $25 \mid-30$ & $30 \mid-35$ & $35 \mid-40$ \\
\hline 6 & 7 & 13 & 8 & 3 & 5 & 5 & 10 \\
\hline
\end{tabular}

Fonte: dados da pesquisa

Cabe destacar que o número de professores (13) com menos de 10 anos de magistério é relativamente pequeno comparado com o total (57). Outra informação que chama atenção é o número de professores que já possui tempo para se aposentar e assim não o fez.

A sexta questão procurou identificar o tempo de trabalho dos professores na instituição. O Quadro 5 mostra a distribuição por faixas, em anos, de tempo de magistério dos professores na instituição.

Quadro 5: Distribuição por tempo de trabalho na instituição.

\begin{tabular}{|c|c|c|c|c|c|c|c|}
\hline $0 \mid-5$ & $5 \mid-10$ & $10 \mid-15$ & $15 \mid-20$ & $20 \mid-25$ & $25 \mid-30$ & $30 \mid-35$ & $35 \mid-40$ \\
\hline 32 & 1 & 3 & 7 & 6 & 1 & 6 & 1 \\
\hline
\end{tabular}

Fonte: dados da pesquisa

Cabe destacar que o número de professores com menos de 5 anos de magistério na instituição é bem significativo, ou seja, 32 em um universo de 60. Pode-se considerar, neste quesito, o fato de o professor substituto (21) não poder ter seu contrato renovado para além de dois anos consecutivos.

\section{RELAÇÃO E INTERAÇÃO COM A INFORMÁTICA}

Com a finalidade de identificar as relações e interações dos professores com a informática Ihes foram apresentadas nove questões relativas ao tema. Essas questões tiveram como objetivo coletar informações se os professores possuíam: computador, notebook e/ou net book, conhecimento (experiência) ${ }^{4}$ e cursos na área de informática. Além de captar suas opiniões sobre as vantagens e ou desvantagens do uso de recursos de informática no processo de ensino e aprendizagem.

A primeira questionou os professores se possuíam computador. Todos os 57 declararam possuir computador. A segunda questionou os professores se possuíam notebook ou net book. Dos 57 professores 56 declararam possuir notebook ou net book.

A terceira questionou os professores sobre ter algum conhecimento na área de informática. 52 afirmaram possuir, 4 afirmaram não possuir e 1 não respondeu a essa pergunta.

\footnotetext{
${ }^{4}$ Conhecimento (experiência) a partir de agora, ao longo do texto, será indicado apenas por conhecimento.
} 
A quarta questionou os professores sobre ter realizado algum curso na área da informática. 46 responderam já ter realizado, 10 responderam não ter feito e 1 não respondeu a essa pergunta.

Quanto ao conhecimento e cursos realizados na área de informática, os professores, em sua maioria, citaram: editores de texto, planilha eletrônica, apresentações e ferramentas básicas da internet.

A quinta questão procurou identificar a utilização de recursos de informática para assuntos particulares. A sexta procurou identificar a utilização de recursos de informática para assuntos profissionais. A sétima procurou identificar a utilização de recursos de informática como apoio ao processo de ensino e aprendizagem. 53 professores responderam já ter utilizado para fins particulares, 55 para fins profissionais e 51 como apoio ao processo de ensino e aprendizagem.

Os recursos de informática mais citados como utilizados para assuntos particulares foram: correio eletrônico, pesquisas para compra, realização de viagens e informação de assuntos gerais.

Para assuntos profissionais, o PF8 apresenta uma boa síntese da posição da maioria dos professores. "Elaboração de provas e roteiros de atividades em sala de aula" (PF8).

Quanto ao uso de recursos de informática como apoio ao processo de ensino e aprendizagem a maioria dos professores afirmou utilizar: apresentações no PowerPoint, exibição de vídeos e preparação de material didático (textos e provas).

A oitava questão procurou captar a opinião dos professores quanto às vantagens no uso de recursos de informática no processo de ensino e aprendizagem. 56 professores pensam haver vantagens e 1 informa não haver vantagens.

Dentre as vantagens citadas destacam-se:

- Otimização do tempo, qualidade de imagens e representação; aplicação das possibilidades de comunicação para alem da sala de aula. (PF1);

- Agilizar a informação e seus recursos tornam as aulas mais interessantes. (PF2);

- Visualização/simulação contribuem no processo de aprendizagem. (PF4);

- Agilidade, visão de esquemas e processos complexo de serem feitos no quadro. (PF5);

- Vários fenômenos físicos podem ser evidenciados através de vídeos, e muitas vezes são difíceis de serem reproduzidos ou até mesmo impossiveis na nossa região. (PF11);

- Facilidade de visualização de imagens, processamento de dados, busca de informação, simulação de situações difíceis de serem reproduzidos. (PF15);

- São dinâmicos, atrativos e refletem uma linguagem da geração atual de alunos. (PQ3);

- Rapidez, facilidade de acesso e atualidade. (PQ10);

- Para visualização de gráficos. (PM9); e

- Permite completar lacunas que ocorrem quando falha o abstrato. O recurso audiovisual completa ou substitui, informalmente formaliza um conteúdo. (PM18). 
A nona questão procurou captar a opinião dos professores quanto às desvantagens no uso de recursos de informática no processo de ensino e aprendizagem. 36 professores responderam ver algum tipo de desvantagem enquanto 21 responderam não ver desvantagem.

Dentre as desvantagens citadas destacam-se:

- Se o recurso for utilizado apenas para reforçar uma atitude passiva do aluno. (PF1);

- Quando o ensino se baseia unicamente em visualizar. (PF4);

- Em termos de pesquisa os alunos podem fazer cópias sem mesmo ler o seu próprio trabalho. (PF11);

- Instituições com poucos recursos financeiros não tem como oferecer tais recursos. (PQ3);

- O uso inadequado dos recursos da informática. (PQ6);

- Não sendo bem direcionado torna o trabalho individual. (PB2);

- O tempo e dificuldade de acesso aos laboratórios de informática. (PM16);

- Falta de preparo dos usuários. (PM7);

- Quando seu uso não é precedido pela definição de objetivos claros e precisos. A metodologia precisa antecipar o computador. (PM10); e

- Se for utilizado sem preparação ou apenas para ilustração. (PM14).

O PM10 destaca um ponto importante quando menciona "A metodologia precisa antecipar o computador". Infere-se daí que é necessário construir novas metodologias para se obter melhores resultados com o uso dos recursos das TICs na educação. O que corrobora com a posição de Feldkercher e Matias (2010), quando afirmam que se fazem necessárias novas metodologias que levem em consideração essa nova possibilidade de ensino, pois não bastam tecnologias para que a aprendizagem ocorra.

\section{RELAÇÃO E INTERAÇÃO COM A INTERNET}

Com o objetivo de se identificar as relações e interações dos professores com a internet, foram-lhe apresentadas nove questões relativas ao tema. Tais questões objetivaram obter informações relativas a terem: conhecimento, realizado cursos, acesso e o número de vezes que acessam a internet por semana. Também procurou identificar suas opiniões sobre as vantagens e ou desvantagens do uso de recursos da internet no processo de ensino e aprendizagem.

Quatro questões procuraram identificar se os professores possuíam algum conhecimento em internet, se já realizaram algum curso, se tem acesso a ela e o número de vezes que acessam por semana.

A primeira questão relativa a possuírem algum conhecimento em internet, 52 professores responderam possuir e 5 disseram não possuir conhecimento.

No tocante a conhecimento em internet, em geral, as opiniões registradas pelos professores, podem ser sintetizadas com o ter conhecimentos básicos para navegar, acessar email e realizar pesquisas. Cabe destacar o registro deixado pelo PM6: "Só o básico adquirido com o uso frequente". Entende-se que esse posicionamento sinaliza que o conhecimento, da atual geração de professores, relativo à internet depende muito do esforço individual de cada 
educador. A declaração do PM6 aponta no sentido de que a aprendizagem só ocorre se houver interesse e/ou necessidade de aprender por parte do sujeito que aprende.

A segunda questão sobre já terem realizado algum curso na área da internet, 20 professores afirmaram já ter realizado e 37 afirmaram não ter realizado. Ao se comparar os dados dessa questão com os dados da questão anterior, pode-se inferir que a declaração deixada pelo PM6 é valida para outros professores, pois, 52 professores afirmaram possuir conhecimento em internet e 37 professores afirmaram não ter realizado nenhum curso na área da internet. 0 número de professores que declararam possuir conhecimento e os que declararam não terem realizado cursos na área de internet corroboram com a declaração do PM6.

A terceira questão relativa a terem acesso à internet, todos os 57 professores responderam ter acesso à internet tanto em casa quanto no local de trabalho.

A quarta questionou sobre o número de vezes que acessam a internet por semana. 0 Quadro 6 mostra as respostas dos professores a esse questionamento.

Quadro 6: número de acesso à internet por semana

\begin{tabular}{|c|c|c|c|c|c|}
\hline Número de vezes por semana & 7 ou mais & 6 & 5 & 4 & 2 \\
\hline Número de professores & 48 & 1 & 2 & 5 & 1 \\
\hline
\end{tabular}

Fonte: dados da pesquisa

Pelas informações tabuladas no Quadro 6 pode-se inferir que os 57 professores estão de alguma forma inseridos no mundo da internet.

A quinta questionou sobre a utilização de recursos da internet, pelos professores, para assuntos particulares; a sexta para assuntos profissionais e a sétima como apoio ao processo de ensino e aprendizagem. 54 professores responderam já ter utilizado para fins particulares, 52 para fins profissionais e 45 como apoio ao processo de ensino e aprendizagem.

Os recursos da internet mais citados para assuntos particulares foram: acessar email, citado praticamente por todos os professores, e redes sociais, compras, download de filmes e músicas, obter informações, pesquisa escolares, programação de eventos e trabalhos particulares.

Para assuntos profissionais, os recursos de internet mais citados, foram: avisos, comunicação com outros professores, disponibilização de atividades, divulgação de resultados de provas, download de filmes didáticos. Além de envio de: arquivos aos alunos, email para alunos e para colegas de trabalho, indicação de sites de pesquisa para alunos, pesquisa de softwares educacionais, pesquisa escolar e uso do sistema acadêmico para lançar notas.

Como apoio ao processo de ensino e aprendizagem, os recursos de internet mais citados foram: animações, filmes e simulações disponíveis na internet, blog e disponibilização de conteúdos de aula no sistema acadêmico. Além de exemplos de aplicações tais como: Geogebra, Google Docs, pesquisas com estudo dirigido, provas online (jogos), sites de busca em sala de aula, sites de pesquisa e vídeos do Youtube. 
A oitava questão procurou captar a opinião dos professores quanto às vantagens e a nona procurou captar a opinião dos professores quanto às desvantagens do uso de recursos da internet no processo de ensino e aprendizagem.

No quesito vantagens do uso de recursos da internet no processo de ensino e aprendizagem 54 professores responderam que pensam haver vantagens, 2 pensam não haver vantagens e 1 não respondeu a essa pergunta.

Dentre as vantagens citadas destacam-se:

- O aluno ter contato com vários formatos de divulgação científica. (PF2);

- Visualização de um experimento e análise de uma simulação experimental. (PF4);

- Muitos materiais didáticos e de pesquisa à disposição. (PF5);

- Facilidade de interação simultânea com todos os alunos - troca de opiniões, etc. (PF7);

- Possibilidade de interação com os estudantes além do horário da aula seja para orientação ou para esclarecimento de dúvidas. (PF12);

- Postar notícias recentes; abordar assuntos científicos polêmicos e apresentação de figuras, imagens e gráficos complexos. (PF14); e

- Sair da rotina, complementar o conteúdo sistemático contido nos livros, fonte inesgotável de informação e pesquisa. (PF14).

No quesito desvantagens do uso de recursos da internet no processo de ensino e aprendizagem 30 professores responderam ver algum tipo de desvantagem, 26 responderam não ver nenhum tipo de desvantagem e 1 não respondeu a essa pergunta.

A maioria dos professores apresentou como desvantagens: conteúdo nem sempre confiável; o procedimento do estudante de copiar/colar e falta de preparo do professor para trabalhar uma metodologia adequada a essa nova realidade contemporânea.

$\mathrm{Na}$ opinião de alguns dos professores, existem desvantagens no uso de recursos da internet no processo de ensino e aprendizagem. Dentre as desvantagens citadas destacam-se:

- Quando o ensino se baseia unicamente em visualizar. (PF4);

- O aluno utiliza material pronto e apenas faz uma cópia. (PF7);

- Em termos de pesquisa, os alunos podem fazer cópias sem mesmo ler o seu próprio trabalho. (PF11);

- Os mesmos vícios do processo de exposição tradicional, normalmente os professores não recebem formação para apresentação e elaboração audiovisual. (PF14); e

- Perda do entendimento do processo, do foco e concentração devido à facilidade de navegação, etc.. (PF15).

\section{RELAÇÃO E INTERAÇÃO COM AMBIENTES VIRTUAIS DE APRENDIZAGEM (AVAS)}

Seis questões referentes às relações e interações dos professores com os AVAs tiveram como objetivo coletar informações relativas ao conhecimento dos professores quanto à realização de cursos e ao uso de recursos dos AVAs como apoio ao processo de ensino e 
aprendizagem, além de procurar captar suas opiniões sobre vantagens e ou desvantagens do uso de recursos dos AVAs no processo de ensino e aprendizagem.

A primeira questão procurou identificar se os professores possuíam algum conhecimento em AVAs. 23 professores responderam possuir noções elementares e 34 disseram não possuir nenhum conhecimento.

A segunda questão procurou identificar se os professores tinham feito algum curso sobre o uso dos AVAs. 24 professores responderam ter feito algum curso com noções elementares sobre os AVAs e 33 responderam não ter feito nenhum curso.

A terceira questão avaliou os professores sobre já ter utilizado algum recurso dos AVAs. 9 professores responderam já ter utilizado algum recurso e 48 responderam não ter usado nenhum recurso. A quarta pergunta questionou os professores sobre o uso de recursos dos AVAs como apoio ao processo de ensino e aprendizagem. 7 professores responderam já ter utilizado e 50 responderam não ter utilizado. A maioria dos professores que respondeu já ter utilizado algum recurso dos AVAs justificou que o fizeram de forma incipiente.

A quinta questão procurou captar a opinião dos professores sobre vantagens do uso de recursos dos AVAs no processo de ensino e aprendizagem. 24 professores indicam que há vantagens, 11 pensam que não há e 22 não responderam a essa pergunta.

A sexta questão procurou captar a opinião dos professores sobre desvantagens no uso de recursos dos AVAs no processo de ensino e aprendizagem. 15 professores responderam ver algum tipo de desvantagem, 21 responderam não ver nenhum tipo de desvantagem e 21 não respondeu a essa pergunta.

No que toca a opinião dos professores sobre as vantagens e ou desvantagens, a maioria não quiseram se manifestar, pois se julgam incapazes de fazê-lo por não ter conhecimento suficiente sobre os AVAs.

\section{RELAÇÃO E INTERAÇÃO COM OS OBJETOS DE APRENDIZAGEM (OA)}

Seis questões foram referentes às relações e interações dos professores com os Objetos de Aprendizagem (OA). Essas questões tiveram como objetivo captar informações relativas a conhecimentos dos professores, cursos e uso de recursos dos OA como apoio ao processo de ensino e aprendizagem. Também procurou captar suas opiniões sobre vantagens e ou desvantagens do uso de recursos dos OA no processo de ensino e aprendizagem.

A primeira questão procurou identificar se os professores possuíam algum conhecimento dos OA. 20 professores responderam possuir algum tipo conhecimento, 30 responderam não possuir conhecimento e 7 não responderam a essa pergunta. De acordo com as declarações dos professores que afirmaram ter algum conhecimento em $O A$ pode-se inferir que esse conhecimento é ainda incipiente.

A segunda questão procurou identificar se os professores já haviam feito algum curso sobre o uso dos OA. 7 professores responderam já ter feito, 49 responderam não ter feito e 1 não respondeu a essa pergunta. 
A terceira pergunta questionou os professores sobre o uso de recursos dos OA. 16 professores responderam já ter utilizado, 36 responderam não ter utilizado e 5 não responderam a essa questão.

A quarta pergunta questionou os professores sobre já ter utilizado algum recurso dos OA como apoio ao processo de ensino e aprendizagem. 14 professores responderam já ter utilizado, 36 responderam não ter utilizado e 7 não responderam a essa questão. 0 nível de relação e interação da maioria dos professores fica bem representado pelo questionamento: "Depende do conceito?! O que é O.A??", deixado pelo PM7.

A quinta questão procurou coletar a opinião dos professores sobre as vantagens do uso de recursos dos OA no processo de ensino e aprendizagem. 21 professores responderam que pensam haver vantagens, 18 pensam não haver vantagens no uso desses recursos e 18 não responderam a essa pergunta.

A sexta questão procurou captar a opinião dos professores sobres as desvantagens do uso de recursos dos OA no processo de ensino e aprendizagem. 5 professores responderam ver algum tipo de desvantagem, 33 responderam não ver nenhuma desvantagem e 19 não responderam a essa pergunta.

Em sua maioria, os professores ao serem questionados sobre as vantagens e ou desvantagens do uso de recursos dos OA no processo de ensino e aprendizagem, responderam que não sabiam especificar por falta de melhor conhecimento do assunto.

\section{RELAÇÃO E INTERAÇÃO COM AS TECNOLOGIAS DA INFORMAÇÃO E COMUNICAÇÃO (TICS)}

Três questões foram relativas às relações e interações dos professores com as (TICS). Uma questão procurou identificar se o professor em sua formação profissional recebeu orientação (treinamento) sobre o uso de recursos das TICs no processo de ensino e aprendizagem. Nesse quesito, 11 professores responderam que sim, 44 responderam que não e 2 não responderam a essa questão.

A segunda questão procurou identificar se o professor recebe ou já recebeu incentivo para fazer uso dos recursos das TICs no processo de ensino e aprendizagem. Nesse quesito, 3 responderam já ter recebido, 52 responderam não ter recebido e 2 não responderam a essa pergunta.

A terceira questão procurou identificar se o professor se sente à vontade para utilizar, avaliar criticamente e criar novas possibilidades pedagógicas, partindo da integração dos recursos das TICs ao processo de ensino e aprendizagem. A esse questionamento, 20 professores responderam que sim, 30 responderam que não e 7 não responderam a esse questionamento.

Algumas justificativas foram apresentadas pelos professores sobre esse questionamento. Das quais foram selecionadas as seguintes:

- Por não ter o domínio ou desconhecer a ferramenta em toda sua potencialidade eu não me sinto confortável para utilizar tais recursos. (PF2);

- Não sei avaliar (preciso conhecê-las primeiro). (PF5);

- Não, gostaria de conhecer melhor esses recursos e suas potencialidades. (PF12); 
- Embora não tenha recebido treinamento oficial julgo que é um recurso válido desde que tenha uma metodologia voltada para o processo de ensino e aprendizagem. (PF15);

- Para utilizar sim, pois seria uma aprendizagem comum para aluno e professor. No entanto, avaliar e criar possibilidades pedagógicas talvez sejam mais difíceis, pois necessita-se mais tempo para uma avaliação junto aos alunos (PQ1);

- Não conheço o assunto para dizer sobre ele. (PQ6);

- Novos métodos e tecnologias devem ser testados nos processos de ensino para incentivar os alunos no aprendizado. (PB4); $e$

- Teria que ter o conhecimento. (PM19).

Assim, a maioria dos professores investigados manifestou-se interessada em conhecer e aprender como utilizar as TICs no processo de ensino e aprendizagem, mostrando disposição para aprender inovações que favoreçam este processo.

\section{ALGUMAS REFLEXÕES SOBRE AS JUSTIFICATIVAS DOS SUJEITOS DA PESQUISA}

$\mathrm{Na}$ caracterização do sujeito, observa-se que a maioria dos professores se situa na faixa de 30 a 50 anos. No aspecto formação, 40 dos 57 professores são doutores e/ou mestres. Quanto ao regime de trabalho, 36 são efetivos e 21 são professores substitutos. Por questão legal, o professor substituto não pode ter seu contrato renovado por mais que dois anos. Isso causa um rodízio muito grande de professores substitutos e compromete o trabalho em equipe por área de atuação. A distribuição, por tempo que leciona, ficou bem diluída. Por sua vez, o tempo que leciona na instituição concentrou, em sua maioria, na faixa de 0 a 5 anos. Acredita-se que essa concentração ocorreu por haver um grande número de professores substitutos.

$\mathrm{Na}$ identificação das relações e interações dos professores com a informática observa-se que a maioria dos professores possui uma relação e interação amigável com a mesma. Amigável porque a maioria utiliza a informática para fins particulares e profissionais e como apoio ao processo de ensino e aprendizagem. O recurso de informática mais usado, segundo as informações coletadas, foi o correio eletrônico. $O$ recurso mais utilizado como apoio ao processo de ensino e aprendizagem foi a apresentação em PowerPoint.

Quando questionados sobre vantagens e ou desvantagens muitas foram as manifestações a favor de ambas. Uma boa síntese das vantagens apresentadas foi dada pelo PF1 "Otimização do tempo, qualidade de imagens e representação; aplicação das possibilidades de comunicação para além da sala de aula". Essa declaração corrobora com o pensar de Heide e Stilborne (2000) que afirmam que as TICs têm um potencial transformador na maneira como os professores podem ensinar e os estudantes podem aprender.

Quanto às desvantagens pode-se sintetizar nas impressões deixadas pelos PQ6 e PM10. "O uso inadequado dos recursos da informática", PQ6; e "Quando seu uso não é precedido pela definição de objetivos claros e precisos. A metodologia precisa antecipar o computador", PM10. Opiniões que corroboram com o pensar de LÉVY (1999); HEIDE e STILBORNE (2000); WARSCHAUER (2006) e FELDKERCHER e MATHIAS (2010), quando afirmam que as mídias por si só, tomadas isoladamente, não irão influenciar o desempenho dos estudantes.

$\mathrm{Na}$ categoria relações e interações com a internet, observa-se que a maioria dos professores possui uma relação e interação amigável. Pode-se confirmar tal observação pelo 
número de professores que declarou: possuir conhecimento, já ter realizado algum curso na área, de ter acesso à internet tanto em casa quanto no trabalho e o número de vezes que acessam a internet por semana. A maioria afirmou ter conhecimentos básicos para navegar, acessar o email e pesquisar. Além do alto índice de professores que declararam utilizar a internet para fins particulares, profissionais e como apoio ao processo de ensino e aprendizagem.

Os professores perceberam vantagens no uso dos recursos da internet. Destacam que o estudante pode: ter contato com várias formas de divulgação científica, realizar simulações, interagir além do horário da aula, seja para orientação ou para esclarecimento de dúvidas e que é uma fonte inesgotável de informação e pesquisa. Posições que coincidem com as de Heide e Stilborne (2000) quando afirmam que com o uso das TICS a sala de aula pode tornar-se um ambiente de aprendizagem mais cooperativo, na qual o professor trabalha de forma a fornecer a direção, a orientação e a inspiração. Por outro lado, identificaram desvantagens como: conteúdo nem sempre confiável, o procedimento do estudante de copiar/colar e falta de preparo do professor para trabalhar uma metodologia adequada com essa nova realidade contemporânea.

No aspecto relações e interações dos professores com os AVAs, quando questionados sobre seus conhecimentos, os professores, em geral, declararam possuir noções elementares. Quanto à terem utilizado algum recurso dos AVAs como apoio ao processo de ensino e aprendizagem, poucos afirmaram já ter utilizado algum recurso dos AVAs. Esses professores que declaram já ter utilizado algum recurso dos AVAs afirmaram que o fizeram de forma incipiente. Sobre as vantagens do uso dos AVAs, alguns acreditam haver vantagens e outros acreditam haver desvantagens. Em termos de vantagens e ou desvantagens, em sua maioria, os professores não quiseram emitir opinião por julgarem-se incompetentes para tal por não terem conhecimento suficiente sobre o AVAs.

$\mathrm{Na}$ categoria relações e interações dos professores com os objetos de aprendizagem (OA), a maioria declarou desconhecer. Poucos também foram os que declararam ter utilizado algum recurso dos OA. Os professores que declararam já ter tido alguma relação e ou interação com os OA afirmaram que são apenas noções elementares. Suas opiniões sobre vantagens e ou desvantagens do uso dos OA são semelhantes à manifestada sobre os AVAs. Ou seja, não quiseram emitir suas opiniões sobre as vantagens e ou desvantagens do uso de recursos dos OA por acreditarem que necessitam de melhor conhecimento do assunto.

O questionamento sobre as relações e interações dos professores com as TICs mostrou que a maioria não recebeu orientação (treinamento) em sua formação e nem incentivo para fazer uso dos recursos das TICs no processo de ensino e aprendizagem. Ao serem questionados sobre se se sentem à vontade para utilizar, avaliar criticamente e criar novas possibilidades pedagógicas, a partir da integração dos recursos das TICs ao processo de ensino e aprendizagem, as justificativas apresentadas são permeadas por dúvidas e incertezas. Como, por exemplo, "por não ter o domínio ou desconhecer a ferramenta em toda sua potencialidade eu não me sinto confortável para utilizar tais recursos" (PF2). Nas justificativas desse item ficou latente o desejo dos professores em conhecer, entender e compreender como integrar as TICS ao processo de ensino e aprendizagem.

\section{ALGUMAS CONSIDERAÇÕES FINAIS}


Esse trabalho teve como objetivo investigar o estágio atual das relações e interações de professores com as TICs. Os sujeitos da pesquisa foram professores que lecionam Ciências e Matemática no Ensino Médio de uma instituição de educação tecnológica situada no estado de Minas Gerais. A coleta de informações foi feita por meio de um questionário. Esse questionário procurou identificar: a caracterização do sujeito, sua relação e interação com a informática, com a internet, com os ambientes virtuais de aprendizagem (AVAs), com os objetos de aprendizagem (OA) e com as tecnologias da informação e comunicação (TICS). Em cada uma dessas categorias, procurou-se obter informações específicas das relações e interações dos sujeitos com elas. Por se tratar de uma pesquisa com uma abordagem qualitativa, mais se preocupou com o significado dos dados e com a compreensão do fenômeno do que com as quantidades. Desse modo, valorizou-se mais as justificativas dadas a cada resposta.

Pôde-se identificar que a maioria dos professores possui uma relação e interação amigável com a informática e com a internet. Alguns professores utilizam tecnologias em seu trabalho docente, com destaque para o uso da internet e do email. A maior parte dos professores reconheceu a potencialidade das Tecnologias da Informação e Comunicação no processo de ensino e aprendizagem. Os professores apontam muitas vantagens e desvantagens para o uso das tecnologias aplicadas à educação. Por outro lado, as relações e interações com os Ambientes Virtuais de Aprendizagem e com os Objetos de Aprendizagem ainda se mostram incipientes.

Foi possível identificar que a maioria dos professores não recebeu formação para trabalhar com as TICs e nem recebeu orientação para utilizar os recursos das TICs no processo de ensino e aprendizagem.

Fica em aberto a necessidade de investigar, como facilitar essa transição entre o passado e o presente da educação e da modernidade das TICs. Disposição para fazê-lo os professores demonstraram em suas justificativas. Afirmar que falta motivação por parte do professor acredita-se que não seja a justificativa. Então qual seria o caminho a ser seguido?

\section{AGRADECIMENTOS}

Gostaria de expressar agradecimentos a CAPES pela concessão da bolsa....

\section{REFERÊNCIAS BIBLIOGRÁFICAS}

1. BARDIN, Laurence. Análise de Conteúdo. Lisboa: Edições 70, 2010.

2. CASTELLS, Manuel. A sociedade em rede: A era da informação: economia, sociedade e cultura; v. 1. São Paulo: Paz e Terra, 1999.

3. FELDKERCHER, Nadiane e MATHIAS, Carmem Vieira. Tecnologias da informação e comunicação aplicadas à educação superior presencial e a distância: o ponto de vista dos professores. Revista Educação e Tecnologia, v. 15. n 3, p. 36-46, set/dez 2010.

4. HEIDE, Ann e STILBORNE, Linda. Guia do Professor para a Internet - completo e fácil; 2.ed. Porto Alegre: Artes Médicas Sul, 2000.

5. LÉVY, Pierre. As tecnologias da inteligência; Rio de janeiro: Ed. 34, 1993.

6. Cibercultura; São Paulo: Ed. 34, 1999.

7. MINAYO, M, C. S. A pesquisa qualitativa. Petrópolis: Vozes, 1986. 
8. MOREIRA, Marco Antonio; MASINI, Elcie F. Salzano. Aprendizagem Significativa: A teoria de David Ausubel. São Paulo: Centauro, 2001.

9. Nascimento, João Kerginaldo Firmino do. Informática aplicada à educação. Brasília: Universidade de Brasília, 2007. 84 p.

10. SANDHOLTZ et. al.. Ensinando com Tecnologia: criando salas de aula centradas nos alunos. Porto Alegre: Artes Médicas, 1997.

11. Tajra, Sanmya Feitosa. Informática na Educação: novas ferramentas pedagógicas para o professor na atualidade. 8. ed. rev. e ampl. São Paulo: Érica, 2008.

12. WARSCHAUER, Mark. Tecnologia e inclusão social: a exclusão digital em debate. São Paulo: Editora SENAC, 2006. 